\title{
Exploring Post Occupancy Evaluation as a Sustainable Tool for Assessing Building Performance in Developing Countries
}

JSACE $2 / 25$

Exploring Post Occupancy Evaluation as a Sustainable Tool for Assessing Building Performance in Developing Countries

Received 2018/07/30

Accepted after revision 2019/01/14

\section{Edidiong Ukpong}

Department of Architecture, University of Nigeria, Nsukka, Nigeria

\section{Aniebietabasi Ackley*}

School of Architecture, Victoria University of Wellington, New Zealand

*Corresponding author: aniebietabasi.ackley@vuw.ac.nz

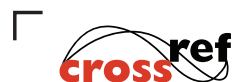
http://dx.doi.org/10.5755/j01.sace.25.2.21176

In recent years, the concept of using Post Occupancy Evaluation (POE) for building performance assessment has attracted much attention globally because of its benefits in enhancing future design decisions. However, developing countries give little or no concern to the practice of improving design outcomes using POEs. In Nigeria, buildings are rarely evaluated once they are handed over to the clients. This study explored the use of POE as a sustainable tool to assess building performance in developing countries with Nigeria as a case study. The method of data collection was firstly through a systematic literature review where existing and current conceptual body of knowledge in peer-reviewed journals, electronic databases (Science Direct and Google Scholar), conference proceedings, and published articles were appraised; with a specific focus on key issues of POE, such as: its definition, evolution, phases, levels, dimensions, benefits and application as a sustainable tool for building performance. The findings from the literature informed the use of interviews to gather the perception of building professionals on the use of POE for building performance assessment. A total of 117 building professionals including architects, engineers, planners and surveyors were interviewed. The data analysis involved descriptive and inferential statistics (frequency count and simple percentages). The study findings revealed that building occupants are a valuable source of information on building performance and that POE methods should be simple and building typology specific. The interviewees suggested that POEs could provide useful benchmarking data to establish best practices for delivering sustainable building developments in Nigeria. It is expected that the findings of this study will encourage policy makers to consider regulations that will enhance the use of POEs for building performance analyses to feed forward the positive and negative lessons learned to improve the design of current and future building developments in developing countries.

Keywords: assessment, developing countries, performance of building, post occupancy evaluation (POE), sustainability.

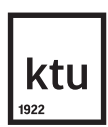

Journal of Sustainable Architecture and Civil Engineering Vol. 2 / No. 25 / 2019 pp. 71-84 DOI 10.5755/j01.sace.25.2.21176 
Introduction

Building users desire buildings to support their yearnings and meet their expectations in accessibility, productivity, health, comfort and satisfaction (Akpan-Idiok and Ackley, 2017; Ackley et al., 2018). This is crucial since people spend up to $90 \%$ of their time inside buildings where they work, study or live in (Ferreira and Cardoso, 2014; Nathanson as cited in El-sharkawy, 2014; Ackley et al., 2017). The idea of sustainability, green buildings, and energy efficiency has made the construction industry and owners to be concerned about how their buildings perform. Building performance can be defined as the degree to which a building can meet any or all these expectations. Several tools and theories have been developed to appraise a building from environmental compliance to energy performance. Post Occupancy Evaluation (POE) is one of the existing tool (Aliyu et al., 2016; Sanni-anibire and Hassanain, 2016). POE is the process of evaluating the building in a systematic and rigorous way after it has been occupied.

In Nigeria, buildings are rarely evaluated once they are handed over to the clients. This lack of appraisal brings about repetition of design mistakes and even when some reassessments are done; it is usually done in a non-systematic manner. The absence of regularized feedback from performance to planning and construction phases becomes ever more relevant under the current conditions which include (Meir, 2008 as cited in Meir et al., 2009): (1) continuous rise in the consumption of energy, both per capita and in absolute terms; (2) the realization that fossil fuels are being depleted and that their use has adverse environmental, health, social, political and security implications; and (3) people spending 80-90 per cent of their lives in buildings, which means that the indoor conditions should have positive imprint on well-being, health and productivity (El Asmar et al., 2014; Jurado et al., 2014; Marchetti et al., 2015; Radwan, 2014; Rovelli et al., 2014; Thornes et al., 2016; Tofful and Perrino, 2015).

POE offers a sustainable building performance tool to create a balance for the increasingly stringent environmental constraints and occupant comfort and satisfaction in buildings. Greater attention has been given to POE studies but majorly in America, Europe and Asia (Leaman et al., 2016; Mallory-Hill et al., 2012; Morrison, 2008; Preiser and Nasar, 2008; Tookaloo and Smith, 2015). However, less attention is given to POE in Nigeria and the few POEs carried out are focused on subjective assessment of buildings (Adedayo and Zubairu, 2013; Ibem et al., 2015; Ilesanmi, 2010; Lawrence, 2012; Nwankwo et al., 2014). This paper focuses on exploring POE as a sustainable tool for building performance in Nigeria, aimed at improving the knowledge of POE in developing countries.

Building performance and its evaluation (using POE) have received increased attention in recent years, particularly with respect to residential and commercial buildings (Brown, 2009; Huat and Bin Akasah, 2011; Olubunmi, 2013; Tanyer and Pembegül, 2010). However, in developing countries; little concern is shown in the practice of building performance evaluation (Agyekum et al., 2016; Olatunji, 2013). Leaman (2004) as cited in Olatunji (2013) stated that building performance is yet to be taken as an area of legitimate interest in the academics, thereby calling for further studies to elucidate POE as a sustainable tool in that direction. Nigeria is yet to be in the fore front of bringing the knowledge and practice of POE as a sustainable tool to bear (Jiboye, 2012). This study explores the benefits of POE as a sustainable tool for building performance in developing countries with a case study of Nigeria.

\section{Building Performance}

Building performance is the behaviour of a product in use in BS5240. It denotes the physical performance characteristics of a building as a whole and/or its parts (Clift, 1995 as cited in Jiun, 2005). It is the capacity of a building to meet its expectation and desired intention. Building occupants' interactions with the physical, business and work environments of a building defines the performance of the building. This performance approach involves the definition of user requirements and performance criteria to be used in a systematic appraisal for predicted or actual 
performance throughout the entire building life cycle (Gajendran, 1998 as cited in Jiun, 2005). There are specialised tools that can be used in measuring building performance and they include; Post Occupancy Evaluation, Building In Use, Concept of Total Building Performance and Building Diagnostics, Building Quality Assessments, ORBIT and BREEAM (Jiun, 2005), Elsaay and Othman (2013) included Building Quality assessment (BQA) and Serviceability tools and methods (STM).

\section{Post Occupancy Evaluation (POE) and its Evolution}

POE is an examination of the effectiveness of occupied built environments for human users that focuses on the assessment of occupant satisfaction and functionality of a space; where effectiveness corresponds to the achievement of personal and organizational goals by the enhancement of physical and organizational factors (Turpin-Brooks and Viccars 2006; Zimmerman and Martin, 2001). "POE is the measurement of building performance throughout the life cycle of a building from initial concept through occupancy such that the information gathered is used to improve future building designs" (Vischer 2001; Zimmerman and Martin, 2001)

The roots of POE are based in academia in the mid-1960s; however POE is based on a much older idea known as the 'performance concept' of building, which dates back to the Code of Hammurabi (1800 BC)(Mallory-Hill et al., 2012). Interesting account of the evolution of POE are recorded in Cooper (2001) and Preiser and Nasar (2008) specifically in the UK. In 1960, Sim van der Rijn and Victor Hsia carried out evaluation case studies of university dormitories even though not called POEs, these evaluations were among the first systematic attempts at assessing building performance from the building users' point of view (Preiser and Nasar, 2008).

In the 80s, lots of POE activity were carried out in the UK, Canada, New Zealand, Australia, and the US on public works projects, government buildings, airports, etc., resulting in very sizeable and significant POE studies. And the first textbook on POE was written by Preiser, Rabinowitz and White in 1988 (Preiser and Nasar, 2008), and since then several terms have been suggested to POE by academics and others working in the industry such as; environmental design evaluation, building in use assessment, facility assessment and post-construction evaluation have been used to depict POE in an attempt to better reflect on its aims and objectives (Council, 2002).

\section{Phases of POE}

Figure 1.0 identifies 3 phases and 9 sub phases in a POE process (Council, 2002).

- The 1st phase: Planning involves review for (1) reconnaissance and feasibility, (2) planning for the resources and (3) the research planning that may be needed for a particular level of POE. Schedule, cost, and human resources are determined; and plans for data collection procedures, time and amounts are the parameters laid out.

- The 2nd phase: Conducting starts with (4) initiating on-site data collection process (5) monitoring and management of data collection procedures, and (6) data analysis.

- The 3rd phase: Applying involves (7) reporting findings, (8) recommending actions and (9) reviewing outcome. This is the most tedious part from the client's view since actions are supposed to be taken at this stage based on the recommendations made. The feed-forward arrow into next building cycle is vital as the best application of POE is its use as a factor in pre-design phases of the building delivery cycle.

POE assesses several aspects of the occupied buildings' functional and technical performance, both chemo-physical (indoor environment quality (IEQ), indoor air quality (IAQ) and thermal performance, acoustic and visual quality), as well as more subjective and interactional (space use, user satisfaction, etc.). POE draws on an extensive quantitative and qualitative toolkit: measurements and monitoring, and methods such as walk-throughs, observations and user satisfaction questionnaires and semi-structured and structured interviews (Meir et al., 2009). 


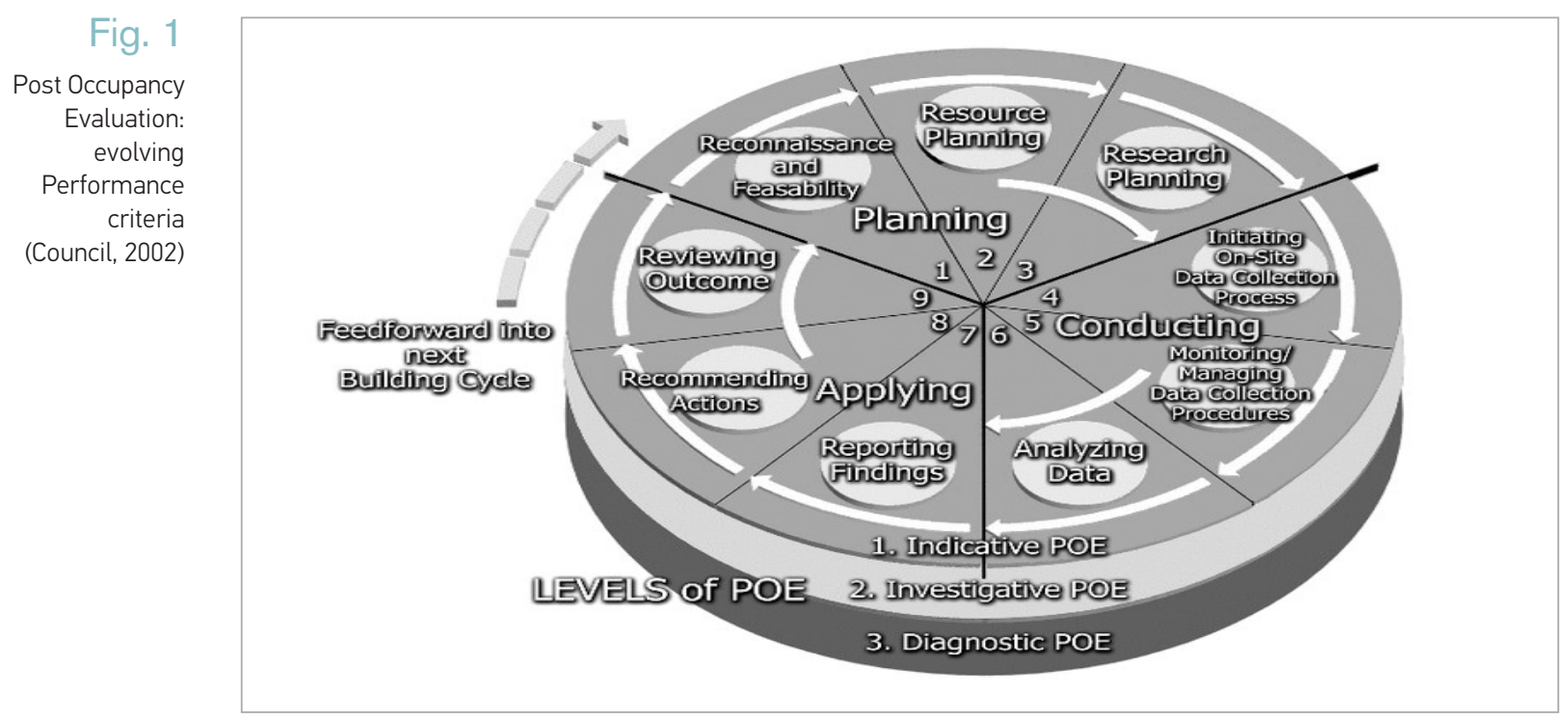

\section{Levels (Types) and Dimensions Of POE}

Most of the literature submitted to these three levels to POE and are summarised as: Indicative, Investigative and Diagnostic POE (Aliyu et al., 2016; Eke et al., 2013; Elsaay and Othman, 2013; Hadjri et al., 2009).

1. Indicative POEs involves quick (two or three hours to one or two days) archival, walkthrough and document evaluations involving structured interviews with key personnel, group meetings with end users as well as inspections. The aim is to highlight major strengths and weaknesses.

2. Investigative POEs are more in-depth analyses, utilising interviews and questionnaires, focus group reviews usually across many buildings of the same or similar type to produce more robust data. This could take a week to several months.

3. Diagnostic POEs are regarded as being the most sophisticated of the methodologies. This takes several months to years. They tend to have a broad system wide focus on many comparable facility types, focusing on a broad range of technological and anthropological areas of research. They produce high validity and generalizability of data collected with the potential of being transformed into guidelines for use in the public realm. Generally, this includes: air-handling, heating, measuring ventilation rates, lighting levels, energy and water usage, $\mathrm{CO} 2$ emissions, thermal, air and visual quality and acoustic performance.

Zimring and Reizenstein in 1980 (as cited in Bhawani, 2015), summarised three dimensions of POE and they include: (1) Generality and Specificity determines the nature of the POE data collected. For example, a study based on impact of floor-plan configurations on users is driven by generic data collection, whereas a study based on specific apartment complex for students is targeted towards specific settings. (2) Breadth of Focus covers the extent of review during an evaluation. The focus of review can be a single physical characteristic of a single setting versus multiple settings. It can also be evaluation of holistic systems such as the social and physical workings of a combination of settings or influence of social trends on the organizational structure that operates in those settings. (3) Timing of application which suggested that while some studies can be conducted on a short-term basis to inform design and planning decisions, some may be conducted on a longer term to develop heuristics and facilitate future planning. Although most POEs have a primary goal, a single study may have multiple goals or multiple studies may have a common goal. 
This research focused on making a case for POE as a sustainable tool for building performance in Nigeria, which gives the focus of this POE specific in terms of the first two dimensions. And for the third dimension, this study is intended to help Nigeria gain from the short and long-term benefits of POE.

\section{Building Performance Assessment Using POE: The Global Case}

A study by Dahlan et al. (2009) focussed on naturally ventilated student housing with ceiling fans and deducted that occupants' perception of indoor thermal comfort was affected by outdoor conditions in agreement with previous research by De Dear and Brager, (2002). Brown and Cole (2009) examined the influence of knowledge on occupant behaviour studying green and non-green academic (departmental) buildings in a university campus. Through the use of POE tools they found that sub-optimal comfort conditions were caused by (Hadjri and Crozier, 2009) absence of timely feedback and poor comprehension. Preiser (2002) highlighted the need for continual building performance evaluation and indicated that POEs are different from other evaluation methods. POEs focus on technical and non-technical parameters providing a holistic performance picture; this was also posited by (Hadjri and Crozier, 2009). Augenbroe and Park (2005) reinforces the importance of measuring building performance addressing key performance aspects such as: energy, lighting, thermal comfort, maintenance and indoor air quality.

Fowler et al. (2005) emphasized that the lack of performance measured data hampered the adoption of sustainable design and construction. This minimizes the savings realized, as stakeholders are simply unaware of the information. Turpin-Brooks and Viccars (2006) discussed the importance of developing robust and effective POEs as part of a sustainable approach to workplaces. They stated that POEs are effective in addressing client satisfaction, and user needs as part of sustainability assessments. Bordass et al. (2009) affirmed Turpin-Brooks and Viccars (2006)'s position.

A study of US data on residential energy consumption, Steemers and Yun (2009)) found that occupant behaviour and socio-economic parameters were also important components in the equation of energy consumption and sustainability demanding POE to salvage the situation. This findings is in agreement with a study carried out by Brown et al. (2010) and Meir et al. (2009). Another study by Guerra-Santin and Itard, (2010) used surveys and questionnaires to discuss the influence of occupants on energy consumption. They studied a residential application in Netherlands and showed that the type of heating/cooling system selected had an influence on occupant consumption behaviour.

The importance of tracking, measurement and on-going building performance awareness was a finding in Masoso (2010) study on waste energy consumption during non-occupied periods of six buildings. The suggested that building performance awareness is the key to reducing energy consumption in buildings and promoting sustainability. This implies that occupants could have a great impact in reducing energy consumption in buildings. POE studies have been carried out worldwide in both the private and public sector, but have rarely led to 'lessons learned' and design changes (Ornstein and Ono, 2010) and the lack of systematic POE use by professionals has led to a situation where mistakes are repeated and every building is a prototype. The impact of occupant behaviour on building energy consumption was studied by Yu et al. (2011). Their findings indicated occupant behaviour as the lead factor influencing building energy consumption.

A study (Martani et al., 2012) carried out on two non-domestic buildings on the MIT campus showing operation of heating, ventilation and air conditioning systems suggested other factors other than occupancy. These factors were closely related to external temperature, however there was a significant correlation between occupancy and electricity consumption. Toftum et al. (2009) studied the energy consumption in two different types of buildings in Singapore one with active cooling and one with passive strategies. They found no significant energy consumption or significant com- 
plaints by those who experienced higher temperatures in the passive building, even though the differential between the two were vastly different. Berker et al. (2011) carried out a study on the user evaluation of sustainable buildings looking at parameters such as indoor climate, mechanical operation, user attitudes and general satisfaction. They highlighted ultimate performance of a building is reliant on users. A study (Yang and Wang, 2013) similar to a study by Klein et al. (2012) focused on the creation of a multi-agent intelligent control system to interact with occupants by responding to their requests and obtaining feedback based on their behaviours.

\section{Post Occupancy Evaluation: The Nigerian Case}

Given the rising cases of building collapse in Nigeria and the poor maintenance of institutional buildings, it is apparent that POE is not well explored in Nigeria. This assertion is supported by Olatunji, (2013) who states that POE is not carried out in most institution buildings in Nigeria (Olatunji, 2013). This has resulted in institutional buildings being regarded as inadequate and deplorable with low occupants' satisfaction (Adamu and Shakantu, 2016; Aluko, 2011; Ojogwu and Alutu, 2009; Ojo et al., 2013; Ubong, 2007). Government office buildings in Nigeria are generally faced with premature but steady and rapid deterioration, decay and dilapidation due to lack of maintenance (Olagunju et al., 2013). A POE carried out in a school building in Nigeria suggested that the negative experiences expressed by the study participants point to the need for building performance evaluation (Olatunji, 2013).

Another study observed that POE as a systematic method of collecting data on buildings in-use has not found wide usage for housing in Nigeria (Jiboye, 2012; Nwankwo et al., 2014). Olatubara and Fatoye (2006) and Olatubara (2008) were cited to have observed that unfortunately most State governments in Nigeria provide housing estates and do not regard building evaluation of these housing estates as an area of legitimate interest (Olubunmi, 2013). There is little factual evidence to ascertain the key problems and the specific factors of ' inadequacy ' or 'non-satisfaction ' in existing public housing estates (llesanmi, 2010), making a call for POEs.

Users of public buildings are generally not satisfied with the building design and design decisions taken with implications that the building has failed to meet the majority of the needs and aspirations of the user of the public buildings in the selected cities in Nigeria (Adedayo and Ayuba, 2013). Motor parks have not met the needs of their users in Minna because they are inadequate and require major transformation (Adedayo and Zubairu, 2013). Another study by Adeniran and Akinlabi, (2012) suggested that because of the form adopted in the architectural design of the Senate Building under study, satisfactory levels of indoor environmental comfort was not achieved and appeared to have been sacrificed for the high aesthetic value achieved.

\section{Benefits of POE as a Sustainable Tool for Building Performance in Nigeria}

Brundtland Commission (1987), defined Sustainable development to be a development that "meets the needs of the present without compromising the ability of future generations to meet their own needs" (ljatuyi Olufunto and Olatunde, 2013). Under the mounting pressure of energy shortage, one approach to minimize the contradiction of the increasing demand for comfort in buildings and the need to decrease the use of energy is to design sustainable buildings in an informed and responsive way (Meir et al., 2009; Zeiler and Boxem, 2008; Zeiler et al., 2007). As a result, integration between end- user needs and building performance is indispensable. POE makes a case in this stand and its short-term benefits include obtaining users' feedback on problems in buildings and the identification of solutions; medium-term benefits include feed-forward of the positive and negative lessons learned into the next building cycle; long-term benefits aim at the creation of databases and the update, upgrade and generation of planning and design protocols and paradigms.

Exploratory research is an examination into a subject to gain further insight identifying issues that could be the focus of future research. The methodology used in this study was firstly a systematic 
literature review which focused on appraising existing and current conceptual body of knowledge, previous published studies bringing to the fore the key issues of POE- its evolution, phases, methods, levels, application as a sustainable tool for building performance and its benefits. Peer-reviewed journals, electronic databases (Science Direct and Google Scholar), and conference proceedings where direct sources of the body of literature. The study reviewed and analysed literature on post occupancy evaluation (POE) and building performance bringing out germane points on POE concept.

The second method used to gather data was through interviewing building professionals to gather their perception on the use of POEs for building performance analyses in Nigeria. Interviews can be defined as a qualitative research technique which involve social interaction with participants to explore their perspectives on an idea (Groat and Wang, 2004). Interviews help to collate the story behind a participant experiences and pursue in-depth information around a topic (McNamara, 1999). Based on the response of the respondents, interviews are completed by the interviewer. In this study, an informal conversational, semi structured face to face interview with predetermined questions were used to gather the perspective of 117 building professionals on the use of POEs for building performance analyses in Nigeria. The data analysis involved descriptive and inferential statistics (frequency count and simple percentages).

Between $16^{\text {th }}$ and $31^{\text {st }}$ November 2018, informal conversational, semi structured face to face interview was carried out with 117 interviewees. The interview allowed each interviewee to express their perspective about POE in Nigeria. The charts and tables below present the responses collated from interviewees.

As shown in Table 1, many interviewees were males 61.5\% ( $n=72)$, between the ages of 26 to 35 years $43.6 \%(n=51)$. Majority of interviewees were architects $41.0 \%(n=48)$ and $40.2 \%(n=47)$ attained a master's degree tertiary education level.

\begin{tabular}{|c|c|c|c|}
\hline Description & & Frequency $(n=117)$ & Percentage (\%) \\
\hline \multirow{2}{*}{ Gender } & Male & 72 & 61.5 \\
\hline & Female & 45 & 38.5 \\
\hline \multirow{4}{*}{ Age } & $18-25$ & 37 & 31.6 \\
\hline & $26-35$ & 51 & 43.6 \\
\hline & $36-50$ & 19 & 16.2 \\
\hline & Above 50 & 10 & 8.5 \\
\hline \multirow{4}{*}{ Field of Practice } & Architect & 48 & 41.0 \\
\hline & Engineer & 31 & 26.5 \\
\hline & Planner & 23 & 19.7 \\
\hline & Surveyor & 15 & 12.8 \\
\hline \multirow{4}{*}{ Qualification } & Diploma & 29 & 24.8 \\
\hline & $\mathrm{BSC}$ & 35 & 29.9 \\
\hline & MSc & 47 & 40.2 \\
\hline & $\mathrm{PhD}$ & 6 & 5.1 \\
\hline \multirow{5}{*}{ Years in Practice } & $0-1$ years & 7 & 6.0 \\
\hline & $2-5$ years & 14 & 12.0 \\
\hline & $6-10$ years & 30 & 25.6 \\
\hline & $11-20$ years & 56 & 47.9 \\
\hline & Over 20 years & 10 & 8.5 \\
\hline
\end{tabular}

\section{Methodology}

\section{Results}

Table 1

Socio-demographic data of Interviewees $n=117$ 


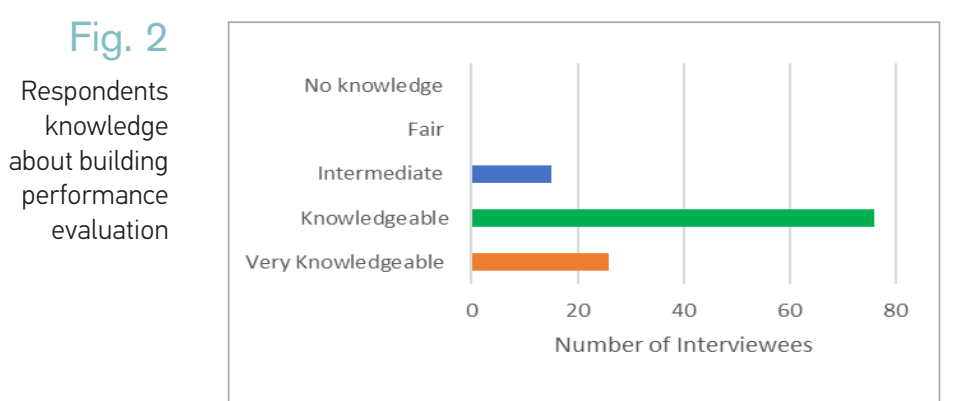

Fig. 3

No of Interviewee that have carried out or been involved in building performance evaluation or research or published any article relating to building performance assessment.

Fig. 4

Satisfaction level of interviewees with the building performance assessment practice in Nigeria
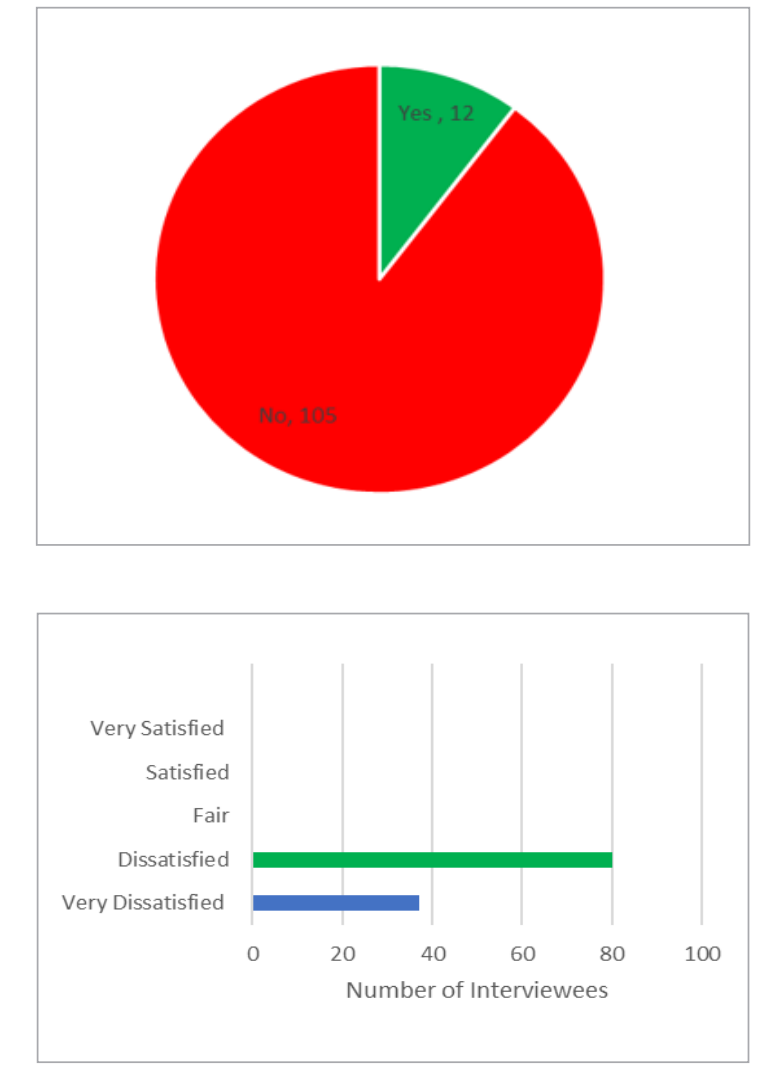

Building Professionals Knowledge of Building Performance Analysis Using POEs in Nigeria

In Fig. 2, majority of interviewees $(n=76)$ stated that they are knowledgeable about building performance evaluation. This could be because majority of interviewees had at least a first-degree qualification and above and are building professionals.

In Fig. 3, majority of interviewees stated that they have not carried out or been involved in building performance evaluation, researched or published any article relating to building performance. The few interviewees who responded "yes" stated that they have been involved in POEs of student's hostel accommodation, motor park facilities assessment, and in some selected building estates in the country. They opined that only few POEs seems to have been carried out in Nigeria. This is evident in Fig. 4 below were majority $(n=80)$ of interviewees stated that they were dissatisfied with building performance assessment practice in Nigeria

In response to the benefits of using POE for building performance assessment, majority of interviewees stated that they were knowledgeable about the merits of using POE to assess a building's performance. These gives concerns on why limited POEs have been carried out in Nigeria. Possible reasons are stated in Table 4.

\section{Fig. 5}

Interviewees knowledge about the merits of using

POE in building performance assessment

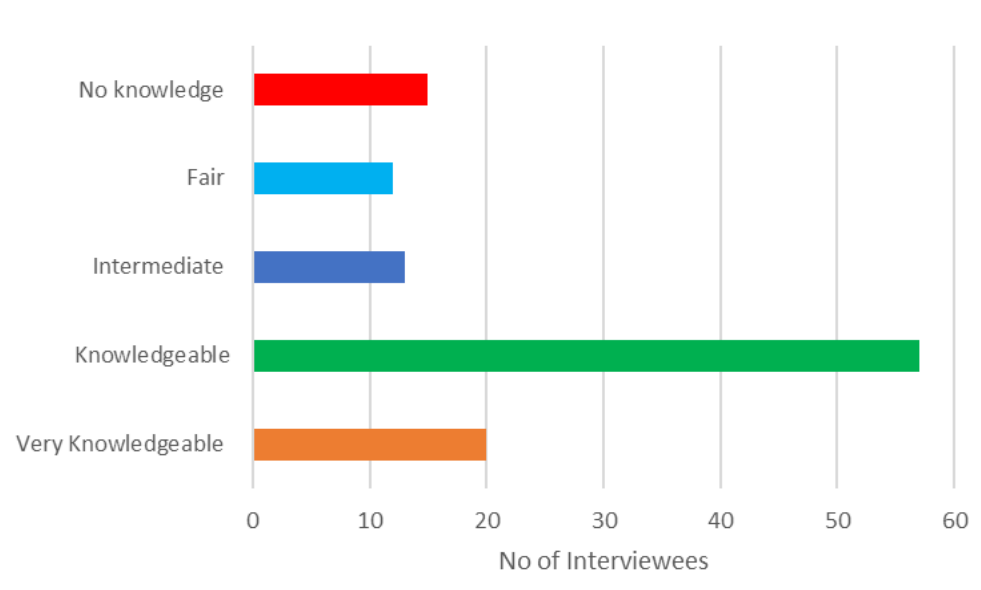




\section{Building Professionals Perception of the Benefits of and Factors Affecting the Use of Building Performance Assessment in Nigeria}

In Table 2, majority of interviewees stated that; improvement in building design following lessons learned from POEs (79.5\%) and forestalling future building failures (77.8\%) were the major benefits of consistent building performance assessments using POEs. This assertion is supported by the literature which suggested that POEs may be beneficial in ascertaining the various causes of building collapse in Nigeria.

\begin{tabular}{|c|c|c|}
\hline Benefits of Building Performance Assessment & Frequency $(n=117)$ & Percentage (\%) \\
\hline Improvement in building design following lessons learned & 93 & 79.5 \\
\hline Forestalling future building failures & 91 & 77.8 \\
\hline Enhancing building efficiency & 38 & 32.5 \\
\hline Improved functionality of the buildings & 53 & 45.3 \\
\hline Effective utilization of resources & 57 & 48.7 \\
\hline Regulation of architectural practice & 75 & 64.1 \\
\hline Expansion of knowledge base on building performance & 69 & 59.0 \\
\hline Improved structural stability and safety features in buildings & 71 & 60.7 \\
\hline Promote the review of building policies & 46 & 39.3 \\
\hline Improvement in service delivery & 44 & 37.6 \\
\hline Provision of new ways of solving building performance problems & 34 & 29.1 \\
\hline
\end{tabular}

In Table 3, lack of policies that encourage POEs, Poor building laws enforcement, high cost of consultancy and professional fees and lack of interest by building professionals were leading factors limiting the sustainable practice of building performance assessment in Nigeria.

\begin{tabular}{|c|c|c|}
\hline Factors Affecting Building Performance Assessment & Frequency $(n=117)$ & Percentage (\%) \\
\hline Lack of awareness of the benefits of POEs & 7 & 6.0 \\
\hline Lack of policies that encourage POEs & 80 & 68.4 \\
\hline Lack of interest by building professionals & 55 & 47.0 \\
\hline High cost of consultancy and professional fees & 69 & 59.0 \\
\hline Poor continuous professional development of professionals & 46 & 39.3 \\
\hline Lack of database culture for archiving information & 5 & 4.3 \\
\hline Poor commitment to sustainability & 43 & 36.8 \\
\hline Poor clients and professionals relationship & 47 & 40.2 \\
\hline Lack of adequate information & 48 & 41.0 \\
\hline Lack of adequate experience in carrying out POEs & 59 & 50.4 \\
\hline Non-involvement of building regulation authorities in construction & 39 & 33.3 \\
\hline None usage of professionals in construction & 37 & 31.6 \\
\hline Government policies & 48 & 41.0 \\
\hline Poor building law enforcement & 66 & 56.4 \\
\hline Ignorance in the part of professionals and professional negligence & 26 & 22.2 \\
\hline Funds mismanagement & 32 & 27.4 \\
\hline
\end{tabular}

\section{Table 2}

Interviewees perspective of the benefits of a consistent building performance assessment practice in Nigeria

\section{Table 3}

Factors that could affect the sustainable practice of building performance assessment in Nigeria 
All interviewees stated that they will recommend the use of POE as a sustainable tool for building performance practice in Nigeria because of the following reasons stated in Table 4.

\begin{tabular}{|c|c|c|c|}
\hline Table 4 & Reasons for Recommending the use of POEs in Nigeria & Frequency & Percentage (\%) \\
\hline \multirow{8}{*}{$\begin{array}{r}\text { Reasons for } \\
\text { recommending the } \\
\text { use of POE as a } \\
\text { sustainable tool for } \\
\text { building performance } \\
\text { practice in Nigeria }\end{array}$} & $\begin{array}{l}\text { To ascertain if the users of the space are satisfied with the } \\
\text { building after occupancy }\end{array}$ & 82 & 70.1 \\
\hline & Lessons learned would be useful in promoting design synergy in Nigeria & 54 & 46.2 \\
\hline & It will promote knowledge on the proper use of building materials & 66 & 56.4 \\
\hline & Improvement of POE know how & 98 & 83.8 \\
\hline & Check reoccurrence of building failures in Nigeria & 102 & 87.2 \\
\hline & It will create professional employment in the building sector & 45 & 38.5 \\
\hline & It will check professional negligence & 92 & 78.6 \\
\hline & It will check the possibility of building failure & 102 & 87.2 \\
\hline
\end{tabular}

From the systematic literature review, it is gathered that little or no attention is given to POE in Nigeria unlike the greater attention given to it as a tool for assessing building performance at the global stage. Highlighted were the definition, evolution, levels, dimensions, and benefits of POE as a sustainable tool for evaluating building performance by involving the owners, professionals, and occupants. POE serves the needs of the owners and it is critical that the building should be evaluated from time to time to ensure that it is serving its intended purposes. Researchers also cautioned that POE methods should be simple and building typology specific. Also highlighted was that industry split incentives, lack of supporting policies, and tools have inhibited adoption of POE processes especially in Nigeria.

From the interview responses, it is evident that building professionals in Nigeria are aware of the benefits of using POEs as a tool for assessing building performance. Interviewees suggested that these benefits include; the use of POE data to improve buildings occupant's health, safety, security, and functionality of a building. This indicates that interviewees understand that POE differs from other types of buildings' similar to the position of some authors (Jiboye, 2012; Nwankwo et al., 2014) performance evaluations.

However, majority ( $n=80$ ) of interviewees were dissatisfied with building performance assessment practice in Nigeria and recommended the use of POEs as a sustainable tool for building performance analyses. Most interviewees suggested that lack of policies that encourage the use of POEs as well as possible high cost of engaging consultants are key factors that affect the sustainable practice of building performance assessment in Nigeria and in developing countries at large. Considering the frequency of building collapse in Nigeria, most interviewees suggested that consistent building performance assessment using POEs could be useful in providing evidence-based data that could help in the improvement of building design and polices to curb future building failures in Nigeria. Some interviewees also suggested that evidence-based data from POEs could promote the review of building policies and expand building professional's knowledge base on building performance analysis.

Furthermore, interviewees suggested that it will be useful to incorporate POEs in building certification process in Nigeria. Nonetheless, the study findings generally support the argument that POEs are important to improving user's satisfaction in buildings which is similar to the position in some studies (Adedayo and Zubairu, 2013; Olatunji, 2013 ), and establishing best practices and lessons learned in delivering building performance assessment in Nigeria.

This study appraised the dimensions and benefits of POE application as a useful tool in building performance assessment. The systematic literature review and responses from interviewees revealed that little or no attention is given to POE in developing countries like Nigeria, unlike the greater attention given to it as a tool for assessing building performance at the global stage. The 
results suggest that building occupants are a valuable source of information on building performance and that POE methods should be simple and building typology specific.

In the Nigerian context, the study findings suggest that the use of POEs in building performance assessment could provide data driven information's that would encourage guideline principles and design criteria to improve similar future projects to forestall building failures. Interviewees recommended the incorporation of POEs in building certification process in developing countries.

The findings of this study are limited to 117 interviewees. Interviewing a larger number of respondents including clients and building regulators as well as using questionnaires to gather the perception of policy makers may provide more insights regarding the sustainable use of POEs for building performance assessment.

In summary, this study supports the argument that POEs are important to improving user's satisfaction in buildings, and establishing best practices and lessons learned in delivering building performance assessment in Nigeria. It is expected that the result of this study will encourage policy makers to consider regulations that enhances the uses of POEs for building performance assessment to feed forward the positive and negative lessons learned to improve the design of current and future building developments in Nigeria.

Ackley, A., Teeling, C., Atamewan, E. Factors Affecting the Shortage and or Provision of Sustainable Affordable Housing in Developing Countries - A Case-Study of Cross River State, Nigeria. Journal of Sustainable Architecture and Civil Engineering, 2018; 27-38. https://doi.org/10.5755/j01.sace.22.1.20573

Ackley, A., Donn, M., Thomas, G. The Influence of Indoor Environmental Quality in Schools A Systematic Literature Review. 51st International Conference of the Architectural Science Association (ANZAScA), 2017;(pp. 625-634). Wellington.

Adamu, A. D., Shakantu, W. Condition assessment of student hostel building on campuses of federal universities in north-central Nigeria. Journal of Construction Project Management and Innovation, 2016; 6(1): 1330-1338.

Adedayo, O. F., Ayuba, P. User perception of location of facilities in public building design in selected cities in Nigeria. Architecture Research, 2016; 3(4): 62-67. https://doi.org/10.5923/j.arch.20130304.02

Adedayo, O. F., Zubairu, S. N. An assessment of facilities in motor parks in Minna, Niger state, Nigeria, through post-occupancy evaluation. Management, 2013; 3(7): 360-367. https://doi.org/10.5923/j. mm.20130307.05

Adeniran, A., Akinlabi, F. Workplace and productivity: A post occupancy evaluation of Lautech senate building, Ogbomoso, Nigeria. Architecture Research, 2012; 2(2): 14-19. https://doi.org/10.5923/j. arch.20120202.03

Agyekum, K., Ayarkwa, J., Amoah, P. Post occupancy evaluation of postgraduate students' hostel, Journal of Building Performance; 2016; 7(1): 97-104.
Akpan-idiok, P., Ackley, A. Sustainable Therapeutic Environment; Impacts of the Indoor Environment on Users Perception of Wellbeing in Public Healthcare Facilities in Calabar Municipality, Nigeria. World Journal of Pharmaceutical and Medical Research, 2017; 3(6): 27-37.

Aliyu, A. A., Muhammad, M. S., Girgiri, M., Singhry, I. M. A review of post-occupancy evaluation as a tool and criteria for assessing building performance. Proceedings of the Academic Conference on Agenda for Sub-Sahara Africa; 2016; 4(1).

Aluko, 0. The Assessment of Housing Situation among Students in the University of Lagos. African Research Review, 2011; 5(20): 104-118. https://doi. org/10.4314/afrrev.v5i3.67345

Augenbroe, G., Park, C. S. Quantification methods of technical building performance. Building Research \& Information, 2005; 33:159-172. https:// doi. org/10.1080/0961321042000325327

Berker, T., Hauge, A., Thomsen, J. User evaluations of energy efficient buildings: Literature review and further research. Advances in Building Energy Research, 2011; 5(1): 109-127. https://doi.org/10.108 0/17512549.2011.582350

Bhawani, S. Post occupancy evaluation: development of an instrument and a process to assess occupant satisfaction in renovated university office settings: a case study approach. Doctoral thesis, Michigan university. 2015. https://doi.org/10.1017/ CB09781107415324.004

Bordass, W., EleyLeaman, A., Eley, J. A guide to feedback and post-occupancy evaluation. Usable Buildings Trust, May,2009: 1-17.

\section{References}


Brown, Z. B. Occupant comfort and engagement in green buildings: Examining the effects of knowledge, feedback and workplace culture. PhD thesis. 2009.

Brown, Z., Cole, R. Influence of occupants' knowledge on comfort expectations and behaviour. Building Research \& Information, 2009; 37(3): 227-245. https://doi.org/10.1080/09613210902794135

Brown, Z. Cole, R. J., Robinson, J., Dowlatabadi, H. Evaluating user experience in green buildings in relation to workplace culture and context. Facilities, 2010; 28(3/4): 225-238. https://doi. org/10.1108/02632771011023168

Cooper, I. Post-occupancy evaluation - Where are Post-occupancyevaluation-whereareyou?, Building Research and Information, March,2001; 29(2): 158163. https://doi.org/10.1080/09613210010016820

Council, F. F. Learning from our buildings: A stateof-the-practice summary of post-occupancy evaluation, 2002; (Vol. 145). National Academies Press.

Dahlan, N. D., Jones, P. J., Alexander, D. K., Salleh, E., Alias, J. Evidence base prioritisation of indoor comfort perceptions in Malaysian typical multi-storey hostels. Building and Environment, 2009; 44(10): 2158-2165. https://doi.org/10.1016/j.buildenv.2009.03.010

De Dear, R. J., Brager, G. S. Thermal comfort in naturally ventilated buildings: Revisions to ASHRAE Standard 55. Energy and Buildings, 2002; 34(6): 549-561. https://doi.org/10.1016/S03787788(02)00005-1

Eke, C., Aigbavboa, C., Thwala, W. An exploratory literature review of post occupancy evaluation. In Proceedings of the International Conference on Civil and Environmental Engineering. Nov. 27, 2013; (28):170-173.

El-sharkawy, M. F. Study on the indoor air quality level inside governmental elementary schools of Dammam City in Saudi Arabia, Int J Env Health Eng, 2014;3:223(1): 30-37. https://doi. org/10.4103/2277-9183.138416

El Asmar, M., Chokor, A., Srour, I. Are building occupants satisfied with indoor environmental quality of higher education facilities? Energy Procedia, 2014; 50(480): 751-760. https://doi.org/10.1016/j.egypro.2014.06.093

Elsaay, H. A. G., Othman, A. A. E. Post-occupancy evaluation: A learning tool for improving the performance of architecture design firms. 2013.

Ferreira, A. M. da C., Cardoso, M. Indoor air quality and health in schools. Jornal Brasileiro de Pneumologia : Publicaçaäo Oficial Da Sociedade Brasileira de Pneumologia E Tisilogia, 2014; 40(3): 259-68. https://
doi.org/10.1590/S1806-37132014000300009

Fowler, K. M., Solana, A. E., Spees, K. L. Building cost and performance metrics: data collection protocol. Pacific Northwest National Laboratory, September, 2005. https://doi.org/10.2172/885473

Groat, L., Wang, D. Architectural Research Methods. New Jersey: John Wiley \& Sons, Inc.; 2004.

Guerra-Santin, O., Itard, L. Occupants' behaviour: Determinants and effects on residential heating consumption. Building Research \& Information, 2010; 38(3): 318338. https://doi.org/10.1080/09613211003661074

Hadjri, K., Crozier, C. Post-occupancy evaluation: Purpose, benefitsandbarriers. Facilities, January, 2009;27. https://doi.org/10.1108/02632770910923063

Huat, N. B., Bin Akasah, Z. A. Building performance analysis model using post occupancy evaluation for energy-efficient building in Malaysia: A review. In 2011 National Postgraduate Conference - Energy and Sustainability: Exploring the Innovative Minds, NPC; 2011. https://doi.org/10.1109/NatPC.2011.6136351

Ibem, E. O., Aduwo, E. B., Ayo-vaughan, E. K. Assessment of the sustainability of public housing projects in ogun state, Nigeria: A post occupancy evaluation approach. Mediterranean journal of social sciences MCSER, 2015; 6(4): 523-535. https:// doi.org/10.5901/mjss.2015.v6n4s2p523

ljatuyi Olufunto, O., Olatunde, A. Sustainable development through architecture : A reflection. International Journal of Engineering, 2013; 3(6): 632-639.

Ilesanmi, A. O. Post-occupancy evaluation and residents' satisfaction with public housing in Lagos, Nigeria. Journal of Building Appraisal, 2009; 6(2): 153-169. https://doi.org/10.1057/jba.2010.20

Jiboye, A. D. Post-occupancy evaluation of residential satisfaction in Lagos, Nigeria: Feedback for residential improvement. Frontiers of Architectural Research, 2012; 1(3): 236-243. https://doi. org/10.1016/j.foar.2012.08.001

Jiun, N. C. Development of Total Building Performance (Tbp) Assessment System for Office Buildings. Doctoral thesis, 2004: National university of Singapore.

Jurado, S. R., Bankoff, A. D. P., Sanchez, A. Indoor air quality in Brazilian universities. International Journal of Environmental Research and Public Health, 2014; 11(7): 7081-7093. https://doi.org/10.3390/ ijerph110707081

Klein, L., Kwak, J., Kavulya, G., Jazizadeh, F., Becerik-Gerber, B., Varakantham, P., Tambe, M. Coordinating occupant behavior for building energy and comfort management using multi-agent systems. Automation In Construction, 2012; 22525-536. https://doi.org/10.1016/j.autcon.2011.11.012 
Lawrence, A. M. Post Occupancy Evaluation of on-campus students hall of residence "a case study of obafemi awolowo hall of residence lleIfe ." Greener Journal of Science, Engineering and Technology Research, 2012; 3(1): 1-11. https://doi. org/10.15580/GJSETR.2013.1.103112175

Leaman, A., Stevenson, F., Bordass, B., Leaman, A., Stevenson, F., Bordass, B., ... Ox, O. Building evaluation : Practice and principles. Building Research \& Information, 2016; 32(August): 564-577. https://doi. org/10.1080/09613218.2010.495217

Mallory-Hill, S., Preiser, W., Waton, C. Introduction to building performance evaluation: Milestones in evolution. Enhancing Building Performance, 2012; 3-18. Retrieved from http://citeseerx.ist.psu.edu/viewdoc/ download?doi=10.1.1.220.4646\&rep=rep1 \&type=pdf

Marchetti, N., Cavazzini, A., Pasti, L., Catani, M., Malagu, C., Guidi, V. A campus sustainability initiative: Indoor air quality monitoring in classrooms. XVIII AISEM Annual Conference, 2015: (1-4). https:// doi.org/10.1109/AISEM.2015.7066774

Martani, C., Lee, D., Robinson, P., Britter, R., Ratti, C. ENERNET: Studying the dynamic relationship between building occupancy and energy consumption. Energy and Buildings, 2012; 47: 584-591. https:// doi.org/10.1016/j.enbuild.2011.12.037

Masoso, O.T. The dark side of occupants' behavior on building energy use. Energy and Buildings, 2010; (42)2: 173-177 https://doi.org/10.1016/j.enbuild.2009.08.009

McNamara, C. General Guidelines for Conducting Interviews. Minnesota. 1999.

Meir, I., Garb, Y., Jiao, D., Cicelsky, A. Post-occupancy evaluation : An inevitable step toward sustainability. Advances in Building Energy Research, 2009; 3(1): 189-220. https://doi.org/10.3763/aber.2009.0307

Morrison, P. Post occupancy evaluation of the Sheffield international college, University of Sheffield. 2008.

Nwankwo, S. I., Diogu, J. O., Nwankwo, C. V, Okonkwo, M. M. Post-occupancy evaluation of modification of residential buildings for effective and efficient mass housing delivery : Case study of Owerri Urban, South-Eastern Nigeria. Int. Journal of Engineering Research and Applications, 2014; 4(2): 5-26. https:// doi.org/10.18848/2154-8587/CGP/v05i02/37434

Ojo, I. C., Ojo, F. K., Olabintan, O. D., Modupe, O. Post Occupancy Evaluation of Privatized Students ' Hostel Case Study of Federal University of Technology, Akure. International Journal of Computer Science and Information Technology \& Security, 2013; 3(3): 237-246.

Ojogwu, C. N., Alutu, A. N. G. Analysis of the learning environment of university students on nigeria :
A case study of university of Benin, Journal of social science, 2009; 19(1): 69-73. https://doi.org/10.1080 /09718923.2009.11892693

Olagunju, R. E., Adedayo, O. F., Ayuba, P., Abiodun, 0 . Maintenance of the federal secretariat complex Minna, Niger State: A post occupancy evaluation approach. Developing Country Studies, 2013; 3(4): 106-116.

Olatunji, A. A. Post-Occupancy Evaluation of Lagos State Polytechnic Facilities: A User-Based System. Journal of emerging trends in engineering and applied sciences, 2013; 4(2): 229-236.

Olubunmi, O. Performance evaluation of state subsidized housing scheme: A case study of Ogun State housing projects. PhD thesis, Covenant university, Ogun State, Nigeria. 2013.

Ornstein, S. W., Ono, R. Post-occupancy evaluation and design quality in Brazil: Concepts, approaches and an example of application. Architectural Engineering and Design Management, 2010; 6(1): 48-67. https://doi.org/10.3763/aedm.2009.0102

Preiser, W. E. Continuous quality improvement through post-occupancy evaluation feedback. Journal of Corporate Real Estate, 2002; 5(1): 42. https:// doi.org/10.1108/14630010310811993

Preiser, W., Nasar, J. Assessing building performance: Its evolution from post-occupancy evaluation. International Journal of Architectural Research, 2008; 2(1): 84-99. https://doi.org/10.1073/ pnas.0703993104

Radwan, A. M. An evaluation of indoor environmental quality and occupant well-being in three southern rural Manitoba school buildings. Master of Science thesis, Department University of Manitoba. 2014.

Rovelli, S., Cattaneo, A., Nuzzi, C. P., Spinazzè, A., Piazza, S. Airborne Particulate Matter in School Classrooms of northern Italy. Int. J. Environ. Res. Public Health, 2014:1398-1421. https://doi.org/10.3390/ ijerph110201398

Sanni-anibire, M. O., Hassanain, M. A. Post-occupancy evaluation of housing facilities : Overview and summary of methods, Journal of Performance of Constructed Facilities, February, 2016. https://doi. org/10.1061/(ASCE)CF.1943-5509.0000868

Steemers, K., Yun, G. Y. Household energy consumption: A study of the role of occupants. Building Research \& Information, 2009; 37(5-6): 625-637. https://doi.org/10.1080/09613210903186661

Tanyer, A. M., Pembegül, T. Post occupancy evaluation in the practice of architecture: A case study of Lütfi Kirdar convention and exhibition centre. METU Journal of Faculty of Architecture, 2010; 27(1): 241 265. https://doi.org/10.4305/METU.JFA.2010.1.13 
Thornes, J., Mavrogianni, A., Wilkinson, P. Impact of climate change on the domestic indoor environment and associated health risks in the UK Article. Environment international · October, 2016. https:// doi.org/10.1016/j.envint.2015.09.010

Tofful, L., Perrino, C. Chemical composition of indoor and outdoor pm2.5 in three schools in the city of Rome, Atmosphere, 2015; (6): 1422-1443. https:// doi.org/10.3390/atmos6101422

Toftum, J., Andersen, R. V., Jensen, K. L. Occupant performance and building energy consumption with different philosophies of determining acceptable thermal conditions. Building and Environment, 2009 44(10): 2009-2016. https://doi.org/10.1016/j.buildenv.2009.02.007

Tookaloo, A., Smith, R. Post occupancy evaluation in higher education. Procedia Engineering, 2015; 118: 515521. https://doi.org/10.1016/j.proeng.2015.08.470

Turpin-Brooks, S., Viccars, G. The development of robust methods of post occupancy evaluation. Facilities, 2006; 24(5/6): 177-196. https://doi. org/10.1108/02632770610665775

Ubong B. Hostel accommodation in tertiary educational institution in Nigeria: to be or not to be. Unpublished conference paper, School of busi- ness education federal college of education (tech) Omoku.2007.

Vischer, J. C. Chapter 3: Post Occupancy evaluation: A multifaced tool for building improvement. (pp. 23-34). United States of America: Federal Facilities Council, The National Academy Press. 2002.

Yang, R., Wang, L. Development of multi-agent system for building energy and comfort management based on occupant behaviors. Energy and Buildings, January, 2013; 56: 1-7. https://doi.org/10.1016/j. enbuild.2012.10.025

Yu, Z., Fung, B., Haghighat, F., Yoshino, H., Morofsky, E. A systematic procedure to study the influence of occupant behavior on building energy consumption. Energy and Buildings, 2011; 43(6). https://doi. org/10.1016/j.enbuild.2011.02.002

Zeiler, W., Boxem, G. Sustainable schools better than traditional schools? TVVL Magazine, 2008; 24-31.

Zeiler, W., Savanovic, P., Quanjel, E. Design decision support for the conceptual phase of the design process, 2007; 1-15.

Zimmerman, A., Martin, M. Post-occupancy evaluation: benefits and barriers. Building Research \& Information, 2001; 29(2): 168-174. https://doi. org/10.1080/09613210010016857

\section{About the Authors}

\section{EDIDIONG UKPONG}

Principal Architect, Directorate of Physical Planning

University of Uyo, Akwa-lbom State, Nigeria

\section{Main Research Area}

Lighting in Buildings, Indoor Environmental Quality, Post Occupancy Evaluation

\section{Address}

University of Uyo, Nigeria

Tel.: +2348060061292

Email: edidiongukpong1983@gmail.com

\section{ANIEBIETABASI ACKLEY}

\section{PhD Researcher}

Faculty of Architecture and Design, School of Architecture, Victoria University of Wellington, New Zealand

\section{Main Research Area}

Sustainable Architecture, Building Performance Evaluation, Indoor Environmental Quality and Health Architecture

\section{Address}

139 Vivian Street, Te Aro Campus, Wellington Tel.: +642102850560

Email: aniebietabasi.ackley@vuw.ac.nz 